\title{
LA PREGUNTA SOBRE EL BARROCO EN EL CINE DE RAÚL RUIZ
}

\author{
Valeria de los Ríos \\ Pontificia Universidad Católica de Chile \\ edelo@uc.cl
}

RESUMEN/ABSTRACT

En 1987, Christine Buci-Glucksamnn publicó "El ojo barroco de la cámara”, un ensayo que marcaría fuertemente las lecturas del cine de Raúl Ruiz. Este artículo pretende analizar la noción de barroco que subyace a este texto y situarlo de modo crítico en relación con la obra del director chileno. La hipótesis central es que la noción de barroco es una categoría asociada a la historia, que desarticula la linealidad y espacializa el tiempo. En el caso de Ruiz, el momento histórico que marca su producción en términos conceptuales y estilísticos es el Golpe de Estado y su posterior salida al exilio, lo que se refleja tanto en sus películas, como en su poética.

Palabras clave: Raúl Ruiz, barroco, cine, Christinne Buci-Glucksmann.

In 1987, Christine Buci-Glucksmann published "The Baroque Eye of the Camera", an essay that strongly marked the readings of the cinema of Raúl Ruiz. The present article aims to analyze the idea of Baroque that underlies this text by Buci-Glucksmann, and at the same time, locate this concept critically in relation to Ruiz's work. The central hypothesis is that the Baroque is a category intimately related to history, that produces a break in history understood as a timeline, and that transforms time into space. In Ruiz's case the historical moment that marks his production in a conceptual and stylistic way, is the military coup and the subsequent experience in exile. This is reflected both, in his films and his poetic.

Keywords: Raúl Ruiz, Baroque, Cinema, Christinne Buci-Glucksmann. 
A pesar de las aprehensiones que al propio director le suscitaba esta clasificación, el trabajo cinematográfico de Raúl Ruiz fue tempranamente emparentado con el Barroco. En 1987, Christine Buci-Glucksmann publicó "El ojo barroco de la cámara", un ensayo que marcaría de manera definitiva las lecturas de la obra del director chileno en el exilio. Sin duda, la noción de barroco evoca una serie de características estilísticas y temáticas que están presentes en la obra de Ruiz. Sin embargo, el mismo rótulo que permite dar nombre o clasificar una obra tan amplia y diversa como la de Ruiz, puede producir como efecto indeseado una homogeneización, simplificación o generalización que reduce las posibles lecturas de una obra.

El propósito de este artículo será indagar en el concepto de barroco aplicado a la cinematografía de Ruiz, para esclarecer a qué se refiere la crítica cuando califica a su obra de "barroca". Además, la hipótesis que se quiere investigar es que el carácter barroco de la obra de Ruiz puede ser historizado, es decir, el barroco aparecería como producto de una circunstancia histórica específica que obliga al director a codificar su obra con ciertas técnicas y procedimientos emparentados con el Barroco histórico. De este modo, se propondrá que es el golpe de Estado y la consecuente salida al exilio el acontecimiento que marca un antes y un después en la obra de Ruiz y que sería el punto de inflexión para una producción que podría ser denominada barroca.

La salida al exilio es un hecho histórico radical, a la vez individual y colectivo, que obliga a Ruiz a vivir territorial y lingüísticamente alejado de su lugar de origen y de su lengua materna, motivo por el cual su obra comienza a desarrollarse en un espacio inventado, ficcional, multilingüístico, en el que se ha borrado la fijeza de los puntos de referencia. En 1983, Pascal Bonitzer afirmó que el humor de Ruiz es el humor del exiliado (29), un humor negro del que fuimos testigos en su célebre Diálogos de exiliados (1975). El sujeto en Ruiz -dice Serge Daney- es el personaje que se siente mal en su lengua, es decir, el que está exiliado de ella: el niño que parodia la frase que no quiere entender y solo retiene su música; una especie de balbuceo, que sube y baja a lo largo de una línea de entonaciones (34). Algunos de estos rasgos estilísticos ya estaban presentes en su obra anterior, pero se ven intensificados con la salida del director al exilio y siguen apareciendo tras su regreso a Chile, a partir de los años noventa, década en que realizó numerosos proyectos en el país. 


\section{BARROQUISMO DE LA MIRADA EN LATINOAMÉRICA O CARACTERIZACIONES CINEMATOGRÁFICAS DEL CINE DE RAÚL RUIZ}

En Las palabras y las cosas, Michel Foucault describe el Barroco como "el tiempo privilegiado del trompe-l'ceil, de la ilusión cómica, del teatro que se desdobla y representa un teatro, del quid pro quo de los sueños y de las visiones; es el tiempo de los sentidos engañosos; es el tiempo en que las metáforas, las comparaciones y las alegorías definen el espacio poético del lenguaje" (58). A esta definición epistemológica del pensador francés puede sumarse como contrapunto la definición del historiador español José Antonio Maravall, quien define al Barroco como un período histórico que surge alrededor del siglo XVII por la crisis económica, los trastornos monetarios, las guerras, el fortalecimiento de la propiedad agraria señorial y el empobrecimiento de las masas, que crean un sentimiento de amenaza e inestabilidad en la vida social y personal, dominada por las fuerzas represivas de la monarquía absoluta. En "El planeta barroco", Serge Gruzinski afirma que en el siglo XVII el arte manierista italiano y de los Países Bajos y las creaciones barrocas de España y Portugal se mezclaron con las tradiciones indígenas y llegaron a cruzar las fronteras de la expansión ibérica para insertarse en otros mundos, de modo que en ese siglo es posible hablar de un "planeta barroco" (113), producto de múltiples transculturaciones. Según Gruzinski, el florecimiento de las formas barrocas en América es inseparable de un sistema mundial de redes administrado desde Amberes, Lisboa, Madrid y Sevilla, de manera tal que esta diseminación del barroco en América resulta inseparable de la monarquía católica $(114)^{1}$. Así, el carácter epistemológico de la estética barroca estaría fuertemente emparentado con la monarquía absoluta y sus efectos como forma política concreta. De este modo, lo barroco en Ruiz también procede de modo analógico al Barroco histórico: como la monarquía absoluta, el

\footnotetext{
Resulta interesante que Gruzinski relacione la idea del "planeta barroco" en el siglo XVII con "la conciencia del inicio de la globalización" (112). La obra de Ruiz pensada como barroca podría indicar un tipo de obra que está consciente de estar situada en una nueva era de globalización, caracterizada por la circulación de sujetos, flujo de mercancías y abundancia de bienes, tal como la caracteriza Gruzinski.
} 
contexto dictatorial funciona como gatillador de la estética barroca: frente a la represión, el exceso; frente a las normas, un intento de subversión ${ }^{2}$.

Idelber Avelar propone un resurgimiento de la estética barroca en contexto de dictadura y postdictadura. En Alegorías de la derrota afirma que las dictaduras funcionaron como un dispositivo del paso de estado al mercado. En la postdictadura, según Avelar, se produce una reaparición de la alegoría, que en la lectura de Walter Benjamin es la figura que caracteriza al periodo Barroco. La alegoría incorporaría las marcas de su tiempo de producción y ofrecería a la mirada la historia en tanto paisaje primordial petrificado (Avelar 14), es decir, como una ruina. El duelo - con el que Avelar caracteriza el momento postdictatorial- estaría marcado por la figura a la vez barroca y alegórica del cadáver, que implica una paralización del tiempo. Muchas de estas figuras que Avelar propone para caracterizar el momento social y cultural de la postdictadura aparecen mucho antes del fin de la dictadura en la obra de Ruiz. En ese sentido, el director chileno en el exilio se anticipa en la incorporación en su cine de alegorías y de otros procedimientos barrocos.

"El ojo barroco de la cámara" es un texto importante que marcó la lectura de la obra de Ruiz principalmente en Francia, donde fue publicado por primera vez. El texto puede ser acusado de etnocentrismo, puesto que ignora las interpretaciones y lecturas del cine de Ruiz antes de su llegada a Francia, y porque su concepción de lo latinoamericano es, hasta cierto punto, estereotipada. Por ejemplo, cuando se refiere a la "oralidad" en el cine de Ruiz, señala que se debe en parte a las "culturas latinoamericanas" en las que "el relato es transmitido y retransmitido" (160). Por cierto, hay un componente oral en las culturas tradicionales latinoamericanas, como en cualquier cultura tradicional pero esto no es privativo de Latinoamérica. La teorización de Buci-Glucksmann vincula los procedimientos de Ruiz con autores canónicos del Barroco español, como Calderón y Quevedo, pero no hay referencias a autores del Barroco americano. El texto subraya las referencias eruditas del cine de Ruiz basadas en autores como Conrad, Stevenson, Joyce, Kafka, Melville, Cervantes y Homero, entre otros (160), y las únicas referencias a

\footnotetext{
Ruiz es lúcido al relacionar la estética barroca con la Inquisición: "utilizar citas y acumularlas hasta el punto de la saturación es un procedimiento barroco. Cada vez que alguien afirmaba no comprender nada de lo que hacía Góngora, él se defendía diciendo: 'Trabajo únicamente con materiales nobles, está Horacio, Virgilio...' Así se defendía contra la Inquisición” (Entrevistas escogidas 108).
} 
autores latinoamericanos son a Lezama Lima ${ }^{3}$ (161), Jorge Luis Borges ${ }^{4}(163)$ y Octavio Paz ${ }^{5}$ (159). No hay referencias al trabajo de Severo Sarduy ${ }^{6}$, quien, radicado en Francia, escribió ensayos sobre el Barroco, ni a un fenómeno literario, ampliamente conocido en el mundo, como el boom latinoamericano. Tampoco hay alusiones al cine de otros países del continente, aunque sí hay referencias a Welles, Von Stroheim, Godard, Buñuel, Antonioni o Pasolini y se menciona solo a un autor de la periferia europea: Manuel de Oliveira ${ }^{7}$.

El texto de Buci-Glucksmann es a la vez teórico y descriptivo, e intenta caracterizar el extraño cine de Ruiz en el contexto de su incipiente popularización (recordemos que el especial dedicado a Ruiz en Cahiers du Cinema data de 1983, al igual que el número especial que le dedicó la Filmoteca española ese mismo año). Quizá la mayor crítica que se le puede hacer al texto -además de su propio barroquismo- es que descontextualiza la noción de barroco, separando sus motivaciones históricas y culturales de sus expresiones estilísticas. Su gran mérito consiste en haber intentado pensar la obra de Ruiz como totalidad, rastreando ciertos rasgos persistentes que le dieran unidad. Por supuesto, esta búsqueda de unidad resulta un propósito alejado de los intereses del propio Ruiz, un apologeta de la dispersión, sin embargo, es posible aventurar que la redacción de La poética del cine, publicada por primera vez en 1995 en Francia y por la misma editorial que publicó el ensayo de Buci-Glucksmann (DisVoir), es una respuesta a

3 Refiriéndose al uso de la sobreimpresión en El techo de la ballena, Buci-Glucksmann afirma: "Hay allí todo un cine de prestidigitación a lo Méliès, que podría ilustrar esta frase de Lezama Lima: 'El paisaje para el sexo del insecto y no para la memoria del hombre'” (161).

$4 \quad$ En relación con La ciudad de los piratas, Buci-Glucksmann señala: "La ley de la ficción ruiziana, su arte de la impostura y de lo falso, podría enunciarse así: 'Mientras dormimos aquí, estamos despiertos en otro lado' (Borges). Uno es varios, una multitud. De ahí que, como en la geometría de la Tlön borgesiana, la geometría visual ignora las paralelas, y cada hombre que se desplaza modifica las formas que lo rodean" (163). Sobre más relaciones entre la obra de Borges y la de Ruiz, ver "Borges and the New Latin American Cinema" de Richard Peña.

El ensayo incluye una cita: "“El ojo piensa, el pensamiento ve, la mirada toca, las palabras arden', como escribió Octavio Paz" (159).

Severo Sarduy abordó el Barroco en varios ensayos como Barroco (1974) y La simulación (1982). Su aproximación al barroco es desde el discurso de la ciencia, ya que lo explica a partir de Galileo, Copérnico y Kepler, mientras que el neobarroco lo entiende a partir de la teoría de la relatividad de Einstein.

Buci-Glucksmann compara La isla del tesoro con El zapato de raso de Manoel de Oliveira, y las entrelaza como "dos estéticas 'barrocas' posibles en este retorno del cine al cuadro y de la imagen 'como imagen' (170). 
la lectura barroca que se convirtió en hegemónica después de la edición del libro titulado Raoul Ruiz con ensayos de Christine Buci Glucksmann y Fabrice Revault D'Allonnes.

En el artículo que Buci-Glucksmann aporta a este libro, la autora propone en primera instancia que el cine de Ruiz se caracteriza -como el Barrocopor un "deseo loco de ver", donde "todo es posible" (143). Es un cine que posee una visión múltiple, anamórfica, espejeante y llena de trampantojos, emparentada con el "imperialismo de la videncia" de Nicolás de Cusa, que se define como una mirada absoluta, omnicreadora y omnidevoradora, que contempla todas las singularidades, todo lo que ocurre (144). Así describe estilísticamente la autora el barroco en Ruiz:

Efectos -artificios técnicos, excesos hiperbólicos del ver, fragmentos fílmicos refilmados...-crean continuamente afectos y seres ambiguos, llevando al espectador exiliado a pasar de una narración a otra, en esas secuencias de archipiélagos, laberintos o espirales, de un cine que vive y hace suya la sintaxis visual de las grandes figuras de las retóricas barrocas de un Gracián o un Tesauro (145).

Curiosamente, aquí la mirada exiliada es la del espectador, quien ve una sintaxis visual desarticulada, sin una narración unívoca, rasgo que formará parte importante de la poética explícita del autor. Para Buci-Glucksmann, la estética barroca de Ruiz se acerca más a la versión de Gracián, con una "retórica amplificada hecha cuerpo" y no a una "de lo sublime y de los éxtasis divinos y erotizados de Bernini" (149). Para Buci-Glucksmann, el cine de Ruiz es "[p]ura imagen de pasaje y de frontera, ella desestabiliza todo lo real" (149). El Cogito barroco del cine ruiziano, sería "veo, entonces soy" (Buci-Glucksmann 151), en la medida en que "hago visible la sombra, los espectros, la muerte viviente, y que practico un canibalismo visual de todas las formas, alzando el lenguaje a la categoría de trampa o de 'juegos del lenguaje"" (151-152). Es interesante que este "canibalismo" visual no se haya asociado al contexto latinoamericano, por ejemplo, a todo el pensamiento en torno a la figura del caníbal, instaurada en el siglo XV con los diarios de Colón, y que más tarde sería retomada críticamente en clave vanguardista en el Manifiesto Antropófago (1928) de Oswald de Andrade, por pensadores comprometidos con la causa cubana como Roberto Fernández Retamar en su ensayo "Calibán" (1971), o por el movimiento cultural tropicalista en el Brasil. Por otra parte, la idea de que el cine de Ruiz desestabiliza lo real y lo pone a prueba a través de diversas trampas pudo ser claramente vinculado 
a la noción de "realismo púdico"8 que Waldo Rojas propuso para describir el trabajo de Ruiz, y que consiste precisamente en considerar la realidad no ya como algo dado, como lo descubierto absoluto, sino como un sistema de ocultamientos (21).

En términos estilísticos son dos los procedimientos barrocos que la filósofa francesa describe como característicos de la estética barroca en Ruiz: primero, la "imagen metonímica" y segundo, el "oxímoron ruiziano". La imagen metonímica corresponde a planos de detalle (imagen cortada, fragmentada, petrificada) que Buci-Glucksmnann asimila a la mirada alegórica en Benjamin. A diferencia del primer plano narrativo, que certifica lo increíble, el primer plano metonímico fractura deliberadamente la narración, la desconecta del tiempo y el espacio dramáticos, introduciendo una lógica propia de la "figura por disparidad" a la que alude Gracián (Buci-Glucksmann 153). Así, por ejemplo, el espacio deviene no euclidiano, ya que la parte es más grande que el todo, o el instante más largo que el día. Ejemplos de esto lo encontramos en múltiples películas de Ruiz, por ejemplo, en La ciudad de los piratas (1983), donde apreciamos un plano desde el interior de la boca de uno de los personajes o en las deformaciones temporales de películas como El tiempo recobrado (1999), El dominio perdido (2005) o La noche de enfrente (2012). Según Pascal Bonitzer, crítico de Cahiers du Cinema y protagonista de algunos films de Ruiz, la estética del simulacro en el cine del chileno está asociada al uso de trucajes múltiples: lentes deformantes, sobreimpresiones, procedimientos Shuftan, máscara-contramáscara, etc., que no se disimulan, y donde la imagen es lo que es, es decir, una ilusión, efecto o trampa visual. En un sentido similar, Youseff Ishaghpour ha señalado que Ruiz utiliza con insistencia el recurso del "falso raccord", es decir, para invalidar el raccord - que garantiza la identidad y la realidad- Ruiz no trepida en intervenir la imagen, triturándola mediante el uso de objetivos y filtros de color (178179). En El techo de la ballena (1982), por ejemplo, vemos claramente el uso de distintos filtros, la implementación de varios trucos y movimientos de cámara, de espejos, sombras y sobreimpresiones. Estas últimas señalan el paso del tiempo: por ejemplo, cuando Anita juega como un fantasma en un paisaje que se supone es la Patagonia, o cuando el antropólogo narrador intenta escribir infructuosamente en su diario de campo y su mano fantasmal

$8 \quad$ El texto de Rojas fue publicado originalmente en 1983 en España, en el número especial de la Filmoteca española. 
y multiplicada no lo acompaña. La película está hablada en varios idiomas y parte de la trama -centrada en una investigación de corte etnográfico-radica en la dificultad de conocer otros lenguajes, específicamente, el lenguaje de los indígenas, que consta de una sola palabra pronunciada con distintas entonaciones. Los indígenas, en cambio -siguiendo el ejemplo del fuegino Jemmy Button-, aprenden italiano, alemán y francés, escuchan discos de música clásica y citan al filósofo y óptico del siglo XVII Baruch Spinoza.

Por otra parte, el oxímoron ruiziano hace coincidir horror y gag, artificio y seducción, en una suerte de facticidad poética, un experimentalismo visual que Buci-Glucksmann ejemplifica con el primer plano de la calavera en $L a$ ciudad de los piratas. El plano remite a las vanidades y anamorfosis del siglo XVII, pero sin conservar nada del dolor del mundo. Trucada y reluciente en extremo, la calavera lleva anteojos de sol. El uso de fantasmas y espectros también constituye un oxímoron, ya que en ellos la muerte se encarna, se visibiliza: los fantasmas en Ruiz son "sombras que hacen ver que comen, que viven" (Entrevistas escogidas 113), como los piratas de Las tres coronas del marinero (1982). Este procedimiento es solidario con la lógica del sueño, que procede mediante una retórica de condensación, desplazamiento y transposición, y está relacionado con el elogio barroco de la nada (Buci-Glucksmann 156).

La lectura que hace Buci-Glucksmann de la obra de Ruiz tiene una clara impronta filosófica que está marcada por el pensamiento de Gilles Deleuze, a quien pertenece el primer epígrafe del ensayo, tomado de La imagentiempo: "Es un cine de vidente, ya no es un cine de acción" (143). El ejemplo paradigmático de lo barroco en Ruiz es la película de 1979 La hipótesis del cuadro robado, basada en una novela de Pierre Klossowski y con fotografía de Sacha Vierny, el mismo director de fotografía que trabajó con Alain Resnais en El año pasado en Marienbad (1965). La película de Ruiz sigue, según Buci-Glucksmann, la estructura elíptica y espiráldica de Borromini (150). La película de Resnais, por su parte, es el ejemplo por antonomasia de la imagen-tiempo para Deleuze, de allí que Buci-Glucksmann utilice esta nomenclatura para referirse al cine de Ruiz. Así, la filósofa realiza una comparación entre las características barrocas del cine de Ruiz y el cine de postguerra definido por Deleuze. Para Buci-Glucksmann en la obra de Ruiz se produce una confusión entre el espectáculo y lo real, entre lo actual y lo virtual. La indiscernibilidad entre estos dos tipos de imagen -la actual y la virtual- es lo que define la "imagen-cristal" deleuziana, cuya figura paradigmática es el espejo, tan presente en la obra de Ruiz. Ya a partir de Las tres coronas del marinero, Buci-Glucksmann ve que el director chileno "a 
partir de la crisis de la imagen-acción y del desarrollo de la 'imagen óptica y sonora' propia del cine moderno [...], se valdría de la imagen-tiempo y de todos los trucajes y trompe-oeil para inscribir la anomalía, lo fantástico en lo cotidiano" (147). A esta estética emparentada con la visión calderoniana en La vida es sueño, cuya adaptación Ruiz filmó bajo el título de Memoria de las apariencias (1986), Buci-Glucksmann la llama "estética del simulacro y el artificio" (148).

En términos narrativos, Ruiz deslineariza el relato y lo multiplica. En el cine del director chileno las relaciones entre el ver y el decir son disonantes:

Espacio de resonancia y de memoria, de ambientación, y la mezcla de voces in, pero por lo general ligeramente desfasadas, pone en escena imágenes y cuadros, sostiene los primeros planos narrativos. Voz del coleccionista o del marinero, voz del recitador y después del niño de Manuel en la isla de las maravillas (1984) todas las voces discursivas de Ruiz son "muertas-vivientes", atópicas, voces de memoria o de ultratumba, que soportan y a veces unifican los laberintos visuales. Dejan oír lo que nos se puede ver, ocupando el lugar del muerto (159).

La voz narrativa interior a la imagen, asegura Buci-Glucksamnn, "certifica lo increíble, lo presentifica alejándolo, sensibiliza lo abstracto de acuerdo con la polisemia barroca de los sentidos" (159). Esta es también la "voz testamentaria" (32-33) de la que habló Serge Daney al describir el uso de la voz en off en Ruiz. La voz en off de La hipótesis del cuadro robado es ejemplo claro de esto, que también está presente en otros films como Le Jeou de L'Oie (1980) o Retorno de un amateur de bibliotecas (1983), que analizaré más adelante.

\section{EL TIEMPO PETRIFICADO: BARROCO E HISTORIA}

Todos los rasgos barrocos descritos pueden ser historizados. En El origen del 'Trauerspiel' alemán, Walter Benjamin relacionó el Barroco con uso de la alegoría, en la que la historia aparece como fragmento y como ruina. Benjamin escribe:

Si con el Trauerspiel la historia entra en escena, esto lo hace en tanto que escritura. La naturaleza lleva 'historia' escrita en el rostro con los caracteres de la caducidad. La fisonomía alegórica de la historia- 
naturaleza que escenifica el Trauerspiel está presente en tanto que ruina. Pero con ésta, la historia se redujo sensiblemente a escenario. Y así configurada, la historia no se plasma ciertamente como proceso de una vida eterna, más bien como decadencia incontenible. La alegoría se reconoce en ello mucho más allá de la belleza. Las alegorías son en el reino de los pensamientos lo que las ruinas en el reino de las cosas. De ahí el culto barroco a la ruina (396).

Así, según Benjamin, en el Barroco ocurre un cambio de conciencia en torno a la noción de temporalidad y de historia. La alegoría entendida como ruina es un escombro, un trozo y un fragmento (Benjamin 397), lo que desafía la noción del tiempo como eternidad e incluso como linealidad. Para Benjamin, el Barroco está marcado fuertemente por los cambios religiosos producto de la Contrarreforma, de ahí quizás también que para Ruiz - estudiante de Teología- el ejemplo del Barroco sea un antecedente y una fuente de inspiración para hablar a partir de una temporalidad fragmentada, quebrada por el Golpe de Estado y por el exilio. Siguiendo a José Antonio Maravall, para quien el Barroco más que un estilo artístico es una estructura histórica, marcada por la monarquía absoluta y la Contrarreforma, Richard Bégin relaciona el cine de Ruiz con la iglesia de los siglos XVI y XVII, que

intentaba crear un vínculo privilegiado entre el hombre y lo divino a través del poder seductor de la representación mimética. Para ello, la Iglesia había confiado al artista la responsabilidad poética de provocar en el sujeto devoto la conducta estética, incitándole a sentirse personalmente responsable de la escena que él percibía en acción. El sujeto debía reconocer en sus propias facultades sensuales el don que le permitiera vincular, de "suturar" entre sí las formas de lo representado y las fuerzas de lo irrepresentable, el don de hacer de un conjunto, la expresión del todo. Así, la Iglesia contrarreformista intentaba, por una parte, conservar la ilusión de un lenguaje piadoso que se constituía en el mismo momento de la contemplación, y, por otra, fortalecer el misterio de la encarnación y la inaccesibilidad del más allá mediante el recurso de una composición profana, que no se cumple sino en la fe. Por lo tanto la representación mimética debe ser formalmente atractiva en la medida en que el sentido de ésta "se realiza en el espectador" (189).

El Barroco se configura así como un momento histórico en el que la imagen ocupa un lugar central, al mismo tiempo, es un momento en que se pone en entredicho la noción misma de representación, de allí que las expresiones 
artísticas y culturales, rebosantes de dobleces y duplicaciones que cuestionan una representación directa de la realidad -lo que hace el símbolo en el Renacimiento- se diseminen profusamente. Este cambio histórico, cultural y epistemológico tiene por cierto una repercusión en la manera en que se configura el receptor o espectador, pero no me referiré a cómo se construye esta figura en el Barroco histórico, sino más bien cuál es la figura de espectador que se desprende de esta concepción barroca del cine de Ruiz. Tanto para Bégin como para Waldo Rojas lo barroco en Ruiz no estaría solo en el uso de múltiples procedimientos ópticos y sonoros, sino en el trabajo exegético que se le asigna al espectador. El relato está siempre en devenir, formando una estética de latencia e incompletud (Bégin 191). A esta idea de objeto inacabado, típico del cine que procede por montaje, Ruiz la vincula con la ruina, figura paradigmática del barroco benjaminiano. En una entrevista realizada por Pascal Bonitzer y Serge Toubiana en Cahiers du Cinéma en 1983, Ruiz afirma:

Tengo un amigo, con el que hice El Territorio, que dice que hay que considerar las películas como ruinas, del mismo modo en que los románticos del siglo XIX consideraban las ruinas: como un objeto estético pero también con cierta nostalgia. Porque una película es en cualquier caso un objeto inacabado, incluso las películas de Coppola. Entonces hay que considerarlas como un jardín inglés donde encontramos ruinas a las que hemos integrado otras cosas y que utilizamos de otro modo. El jardín inglés se construye alrededor de un castillo para perderse. El placer consiste en perderse, no en regresar al castillo para defenderse de los bárbaros (Ruiz en Cuneo 116).

La cita define claramente la noción de cine como conjunto de fragmentos que jamás forman una totalidad. El cine se convierte así en una ruina cuyo objetivo no es dar todas las respuestas, sino funcionar como un laberinto, donde el espectador puede y debe extraviarse. Esta idea del cine como algo inacabado se puede ejemplificar con la película La hipótesis del cuadro robado, en la que se evoca un centro ausente, imprescindible para el relato, de modo que el secreto aparece como fin de toda interpretación y como matriz de toda historia. La idea del fragmento ausente vuelve sensible la condición incompleta del cine. En términos formales el montaje transparente ignora la sutura entre planos, permitiendo mantener la ilusión de naturalidad. Según Bégin, poner en escena el lenguaje y sus procedimientos como lo hace el cine de Ruiz, es señalar la presencia de esta sutura, lo que nos lleva a discernir más allá de la ilusión de naturalidad (192-193). 
De este modo, cobra especial sentido la poética ruiziana en la que cada plano es una película, y si tenemos 250 planos en un film, tendremos en definitiva 250 películas. En esta propuesta estética de Ruiz -que aboga por la fuerza centrípeta del plano ${ }^{9}$ - lo que está ocurriendo es una espacialización del tiempo, del tiempo en su forma más radical, detenido y en decadencia, que Benjamin describiría con la figura arquitectónica de la ruina. El paso de la temporalidad a la espacialidad -idea premonizada por Foucault en su conferencia sobre la heterotopías de 1967 ("De los espacios otros")también está fuertemente arraigado en el cine de Ruiz. En 1980 filmó el cortometraje Le Jeou de L'Oie, en el que escenifica un dilema cartográfico, similar al presentado por Borges en el cuento "Del rigor de la ciencia" ( $E l$ hacedor, 1960), entre mapa y territorio. Bajo la mirada barroca, el mapa como modo de representación va a ser cuestionado en su capacidad misma de representar. Michael Goddard, autor de The Cinema of Raúl Ruiz. Impossible Cartographies (2013), apunta justamente a analizar la obra de Ruiz como una "cartografía imposible". En esta búsqueda de esta categoría espacial en el cine de Ruiz - que puede leerse también como un efecto del contexto del cine en la era de la globalización ${ }^{10}$ - hay un intento por escapar a la denominación barroca, hegemónica, del cine de Ruiz. En su introducción al libro, Goddard señala:

This complex layering of different styles in Ruiz's work is a clear expression of his diasporic experience in that it combines and superimposes styles and sources associated with Latin America

$9 \quad$ Según Adrian Martin, el plano es para Raúl Ruiz: (1) un paradigma y una alegoría; (2) una imagen autorreflexiva o crítica (función recursiva); (3) centrípeto (independiente y autónomo), (4) centrífugo (busca conexión con los planos que le siguen y anteceden; (5) holístico (puede reproducir el movimiento o lógica profunda de un film); (6) tiene potencial combinatorio, pudiendo crear nuevas asociaciones semánticas y sintácticas. (298-299). Para explicar el carácter centrípeto del plano, Martin aclara: "El impulso centrípeto de Ruiz es perseguido incesantemente a través de múltiples medios: cada plano se dobla sobre sí mismo buscando su propio centro de energía y rompe las usualmente estables conexiones con el plano siguiente a través de elaborados movimientos de cámara (que a veces involucran reflejos en espejos $[\ldots])$, ciertos ajustes en el sonido [...], y especialmente, la tendencia de todo el mobiliario de decorado a dejar de estar inmóvil, cobrando vida a través, hacia arriba o hacia abajo, creando muchas distorsiones momentáneas de la perspectiva visual [...]" (301).

10 El primer artículo que intenta situar a Ruiz en una perspectiva cartográfica data de la década de los noventa y es de Jonathan Rosenbaum, autor de "Mapping the Territory of Raúl Ruiz". 
with europeanstlyes, creating a hybrid and complex form of cinema that defies categorisation. A more complex understanding of this cinema can be reached via the idea of the baroque or neo-baroque as Christine Buci-Glucksmann suggests in her essay 'The Baroque Eye of the Camera'. The Baroque is particularly slippery category in the history of art that frustrates attempts to contain it whether in a specific historical period, or geographical location, and in Latin America it continued to play an important role well beyond the period of colonisation (according to Ruiz the Spanish colonisation of South America was itself a baroque act) and arguably up until the work of modern writers like Borges and the whole style of Magical Realism. As Buci-Glucksmann has also shown in her work on Walter Benjamin there is a direct link between the baroque and European modernity and modernism (and one might be tempted to say even postmodernism), passing through figures like Baudelaire and Benjamin itself. In this optic, Surrealism itself, at least in some of its variants can be understood as a particular instance or return of the baroque in relation to modernity ${ }^{11}(5-6)$.

De este manera, el barroco se configura como una herramienta útil para describir el trabajo híbrido y complejo del cine diaspórico de Ruiz, pero al mismo tiempo, aparece como una categoría inespecífica, volátil, difícil de situar temporal y geográficamente. A pesar o quizás por este mismo carácter

11 "Esta compleja estratificación de diferentes estilos en la obra de Ruiz es una clara expresión de su experiencia diaspórica, en la que combina y superpone estilos y fuentes asociadas con estilos latinoamericanos y europeos, creando una forma híbrida y compleja de cine que desafía la categorización. Una comprensión más compleja de este cine puede alcanzarse a través de la idea de barroco o neobarroco, tal como Christine Buci-Glucksmann lo sugiere en su ensayo 'El ojo barroco de la cámara'. El Barroco es una categoría especialmente escurridiza en la historia del arte, que frustra los intentos de contenerla en un periodo histórico específico, o en una locación geográfica. Además, en Latinoamérica el barroco continuó jugando un rol importante más allá de del periodo de colonización (según Ruiz, la colonización española de Sudamérica fue en sí misma un acto barroco) y presumiblemente siguió operando hasta la aparición de trabajos como los de Borges y del estilo del Realismo Mágico. Tal como lo demuestra Buci-Glucksmann en su trabajo sobre Walter Benjamin, hay un vínculo directo entre el barroco, la modernidad europea y el modernismo (uno se ve tentado a decir incluso postmodernismo), pasando por figuras como las de Baudelaire y el propio Benjamin. En esta óptica, el propio Surrealismo, al menos en algunas de sus variantes, puede ser entendido como una instancia particular o como un regreso del barroco en relación a la modernidad". 
escurridizo, es que categorías como el surrealismo ${ }^{12}$-que también se han utilizado para leer la obra cinematográfica de Ruiz- pueden ser entendidas como una variación o un retorno del barroco en el contexto de la modernidad, de modo que el barroco funcionaría en este contexto como una categoría expandida.

Me interesa analizar Retorno de un amateur de bibliotecas (1983) -un cortometraje autoficcional que Ruiz filmó en su primer regreso a Chile luego de salir al exilio tras el Golpe de Estado de 1973- porque en él se ponen en juego varias estrategias barrocas descritas anteriormente: el uso de filtros y movimientos de cámara, la presencia de muertos, del sueño y de la disparidad entre el ver y el decir. Al mismo tiempo, al ser una película de regreso del exilio, hay una cita al momento histórico del Golpe de Estado. En la película hay dos voces en off, la primera de ellas en francés y la segunda en castellano. Esta última, corresponde a la voz del propio Ruiz, que anuncia que algo ha cambiado en su casa de infancia y que esa cosa ausente es indispensable para esclarecer los acontecimientos ocurridos la noche del 10 al 11 de septiembre de 1973. La inclusión de la fecha fatídica del Golpe de Estado señala un momento de inflexión importante, y sirve como marco de referencia histórica para situar la narración fílmica. Se menciona un objeto perdido, como el cuadro ausente en La hipótesis del cuadro robado, y su sola mención obliga al observador a ponerse en el rol del detective. Las imágenes -que nos presentan objetos cotidianos como sillones, figurillas de cerámica, paños de macramé y cuadros decorativos filmados en primer plano, como imagen metonímica según Buci-Glucksmann- se convierten en pistas. La voz narrativa es acusmática, porque el cuerpo que la origina está fuera del campo de la visión. Esto hace que el narrador se presente con una apariencia fantasmal, y que nosotros, los observadores, nos identifiquemos con la perspectiva de la cámara.

El objeto ausente es un libro de tapa rosa, el cual adquiere las características de una metonimia ruiziana. Dice la voz en off: "entonces supe que el rosado era el color que faltaba y que si el color rosa había desaparecido del mundo, era sin dudas, porque un libro había desaparecido de mi biblioteca". El narrador fantasmal visita a antiguos amigos que entregan su testimonio en

12 Para una lectura del cine de Ruiz vinculado al surrealismo, ver Jayamanne, Laleen. (1995). "Life is a Dream". En Kiss me Deadly: Feminism \& Cinema for the Moment. Sydney. Power Publications: 221-251. 
un castellano chilenizado, subtitulado al francés. La voz narrativa anuncia que uno de sus amigos debe leer sus propios subtítulos para saber qué decir. Esta cómica inversión entre habla y escritura señala que esta última antecede a la oralidad, un comentario derrideano quizá inconsciente que revela que el sentido está dislocado. En términos metafóricos, en esta película el cine viene a reemplazar a la memoria, ya que la cámara registra con la clara intención de recuperar al mismo tiempo el objeto perdido y el recuerdo.

Tests ópticos, como el juego con la profundidad de campo, el montaje y el sonido, adquieren una importancia central. Las estrategias empleadas al interior de la diégesis para recuperar ese objeto perdido son la observación, el registro y el sueño. Este último adquiere un poder de conocimiento, pero de carácter fallido. La voz narrativa cuenta que decidió recordar con la ayuda de una siesta relámpago. Sin embargo, su inconsciente -un "inconsciente cinematográfico" absolutamente contagiado por el medio- sueña en blanco y negro. En otro momento, el narrador decide tomar una siesta para pensar. Si el primer sueño distorsionó los colores, el segundo distorsiona el lenguaje: en él el sujeto intenta en vano pronunciar la palabra "vino" en francés. En este punto se hace evidente la superposición entre las dos voces en off: la voz narrativa del chileno y la del locutor francés. En lugar de "vin" (vino) Ruiz pronuncia "vent" (viento), mientras el locutor francés corrige con su perfecta pronunciación. Con ello, Ruiz hace un guiño lingüístico a su condición de expatriado: aquel que habla mal la lengua de su país adoptivo.

El antídoto al sueño es el desplazamiento espacial: el narrador toma la iniciativa de dar un paseo por la ciudad. Durante su periplo, pone en práctica sus aptitudes perceptivas. Mientras observamos una serie de travellings por Santiago, la música en castellano pero subtitulada al francés funciona como una narración paralela. En un guiño autorreferente, la primera canción habla de un personaje que se encuentra de regreso, pero al mismo tiempo está "enterrado en el pasado". Se cuenta que este sujeto se mudó en "los tiempos de la guerra" y sin decir la razón. El relato cinematográfico es entonces la única manera de certificar la experiencia, aunque esté lleno de elipsis y no sea necesariamente un testimonio que intente comunicar una verdad, sino una ficción autobiográfica de carácter lúdico. Según Agamben, el juego ofrece una operación simétrica y opuesta al rito, tiende a destruir la conexión entre pasado y presente, disolviendo y desmigajando la estructura en acontecimientos (107). El espectador-detective es un observador activo que debe interpretar, leer entre líneas, descifrar este relato de reencuentro entre el sujeto y un territorio sembrado de afectos. 
El recurso a la infancia es para Ruiz un artilugio para escapar a las leyes racionales y presentar la posibilidad de mundos posibles. El narrador decide recorrer el pueblo de su segunda infancia, y casi por azar, se encuentra visitando una casa que habitó cuando niño. En el jardín están los mismos árboles, olores y colores. Esto último echa al suelo su teoría del rosa indispensable. Finalmente, el encuentro del libro perdido no se da como resultado de un plan racional sino que por azar: un día antes de su partida, el narrador reconoce en un bar a su mejor amigo, muerto ya hace diez años. Lo ve con una postura bizarra, porque estaba sentado sobre el libro rosa. El narrador anuncia que cuando su amigo parta, recuperará, por fin, el preciado tomo.

Pronunciado esto, la cámara muestra la portada del libro tan buscado. Se trata de Cantos a lo divino y a lo humano en Aculeo, de Editorial Universitaria. Estos cantos son una expresión tradicional de la cultura popular, una composición en décimas, con diez versos octosílabos y rima consonante hecha para ser cantada. Consultado sobre su vínculo con el barroco, Ruiz confesaba que provenía de su gusto por la poesía popular chilena, en la que existe el gusto por la ocultación (Entrevistas escogidas 150). En la película, el narrador comenta que la clave de lo sucedido del 10 al 11 de septiembre es un poema de infancia que la voz narrativa confiesa no haber logrado aprender de memoria. La noche aludida el narrador comprendió que nunca lograría memorizarlo. Hay en esta experiencia de ficción autobiográfica algo de paso forzado a la adultez, y al mismo tiempo, una resistencia a ese paso, como una entrada negativa al mundo del lenguaje, de parte de alguien que no quiere o sencillamente no puede recordar.

A pesar de lo que sugiere el montaje (que el verso corresponde al poema de infancia), se produce un engaño en el espectador: un falso raccord sonoro, ya que en lugar de una de las décimas que muestra la cámara, la voz en off declama la primera estrofa del soneto "Julio" del escritor modernista Julio Herrera y Reissig, cuyos versos aluden al séptimo mes del año, pero al mismo tiempo, hacen referencia -en un guiño autobiográfico- al autor del poema, cuyo nombre es el mismo que el del mes:

Flota sobre el esplín de la campaña una jaqueca sudorosa y fría, y las ramas celebran en la umbría una función de ventriloquia extraña (102)

La no correspondencia entre el libro aludido y el poema que escuchamos -la "ventriloquia" a la que hace referencia el poema-, es un juego barroco que da 
cuenta de una incongruencia entre lo visual y lo auditivo, del mismo modo en que la cámara cinematográfica -ese ojo mecánico que registra recuerdos inventados- no coincide con el yo autobiográfico, que es quien narra esta carta en primera persona. Así, en este cortometraje, Ruiz trabaja sobre la recuperación tal vez imposible de una memoria, la cual se reconstruye a través del sueño, de los afectos, la percepción, la música y del registro automático de la cámara, que ocupa ahora el lugar del sujeto. La ciudad se imagina como un territorio inexistente o perdido, que solo puede ser abordado a través de la construcción de falsos recuerdos de infancia, desde un presente descolorido y tenebroso.

Aquí, el barroco en Ruiz constituye una "economía política"13, es decir, una figura que reúne numerosos procedimientos para hablar de una historia inasible. Lejos de la nostalgia, Ruiz emplea procedimientos barrocos para señalar que lo real existe pero no puede ser narrado. La historia para Ruiz se presenta como fragmentada, pero esta fragmentación como los múltiples planos de un film, aparece como pura potencialidad y el cine, a través del montaje (en un sentido benjaminiano), se presenta como una herramienta para construirla.

Por cierto la noción de barroco no es la única manera de aproximarse a la amplia y diversa obra de Raúl Ruiz y en la actualidad comienzan abrirse nuevas perspectivas para abordar su cine. A lo largo de este texto, intenté desentrañar esta lectura barroca de Ruiz, una categorización que en su momento tomó un carácter hegemónico, pero que a menudo estuvo fuertemente deshistorizada. Tal como fue demostrado, el barroco tiene un fuerte vínculo con el contexto en el que emerge, que en el caso de Ruiz -en versión neobarroca- aparece relacionado al Golpe de Estado chileno y a su experiencia en el exilio. Aún más, el barroco supone una transformación del concepto de historia: se aleja de la idea de linealidad, desarrollo o progreso, y la entiende más bien como fragmento y como ruina, noción que rompe en el caso de Ruiz con cualquier intento de narrar cinematográficamente en un sentido progresivo y lineal, siguiendo los modelos hegemónicos del cine de

13 En una de sus entrevistas, Ruiz declara: “Creo que en Francia resulta muy difícil hacerle comprender a la gente que lo que llamamos Barroco es una economía. Es un modo de economizar, noun derroche. No hay que confundir el Barroco con el Rococó, sino más bien compararlo con algunos restaurantes del sur de Francia donde hay muy poco espacio y en él se mete al máximo número de personas para tener el mayor número de clientes. Es un tipo de economía que funciona" (Entrevistas escogidas 108-109). 
Hollywood $^{14}$. Este giro en la comprensión de la historia supone también un giro espacial: la ruina es una metáfora arquitectónica que supone un lugar, de ahí que en el cine de Ruiz cobre especial importancia el plano y sus fuerzas centrípetas. La crítica barroca a la vida como sueño es en Ruiz una crítica a la noción de representación en todas sus dimensiones. Vista de esta manera, la categoría de barroco, deja de ser una caracterización meramente estilística que clausura las interpretaciones, y abre la posibilidad de comprender el trabajo de Ruiz a partir de una estética situada, aunque siempre cambiante, en la que la transculturación y el contexto histórico, social y económico juegan un papel fundamental.

\section{BIBLIOGRAFÍA}

Agamben, Giorgio. Infancia e Historia. Trad. Silvio Mattoni. Buenos Aires: Adriana Hidalgo Editora, 2007.

Avelar, Idelber. Alegorías de la derrota: la ficción dictatorial y el trabajo de duelo. Santiago: Cuarto Propio, 2000.

Bégin, Richard. "Raúl Ruiz o el Barroco en acción”. El cine de Raúl Ruiz: Fantasmas, simulacros y artificios, Ed. Valeria de los Ríos e Iván Pinto, 181-201. Santiago: Editores Uqbar, 2010.

Benjamin, Walter. "El origen del 'Trauerspiel' alemán”. Obras. Libro I/vol. 1. Madrid: Abada, 2006.

Bonitzer, Pascal. "Metamorfosis". El cine de Raúl Ruiz: Fantasmas, simulacros y artificios. Ed. Valeria de los Ríos e Iván Pinto. Santiago: Editores Uqbar, 2010. 27-30.

Buci-Glucksmann, Christine. "El ojo barroco de la cámara". El cine de Raúl Ruiz: Fantasmas, simulacros y artificios. Ed. Valeria de los Ríos e Iván Pinto. Santiago: Editores Uqbar, 2010. 143-172.

Daney, Serge. "comiendo, hablando". El cine de Raúl Ruiz: Fantasmas, simulacros y artificios. Ed. Valeria de los Ríos e Iván Pinto. Santiago: Editores Uqbar, 2010. 31-34.

Foucault, Michel. Las palabras y las cosas. Buenos Aires: Siglo XXI, 1968.

Goddard, Michael. The Cinema of Raúl Ruiz. Impossible Cartographies. London and New York: The Wallflower Press, 2013.

Gruzinsky, Serge. "Planeta Barroco". Ultra Baroque. Aspects of Post Latin American Art. Ed. Elizabeth Armstrong y Victor Zamudio-Taylor. San Diego: Museum of Contemporary Art, 2000.

14 De aquí emerge la crítica a la "teoría del conflicto central", que está descrita en su Poética del cine. 
Herrera y Reisig, Julio. "Julio". Poesía completa y prosa selecta. Caracas: Biblioteca Ayacucho, 1978.

Isaghpour, Youseff. "Entre espejos y cuadros: La hipótesis del cuadro robado". El cine de Raúl Ruiz: Fantasmas, simulacros y artificios. Ed. Valeria de los Ríos e Iván Pinto. Santiago: Editores Uqbar, 2010. 173-180.

Maravall, José Antonio. La cultura del Barroco. Barcelona: Ariel, 2000.

Martin, Adrian. "Aquí colgando y por allá tanteando: Acerca de 'las seis funciones del plano de Raúl Ruiz"'. El cine de Raúl Ruiz: Fantasmas, simulacros y artificios. Ed. Valeria de los Ríos e Iván Pinto. Santiago: Editores Uqbar, 2010. 291-304.

Rojas, Waldo. "Imágenes de paso". El cine de Raúl Ruiz: Fantasmas, simulacros y artificios. Ed. Valeria de los Ríos e Iván Pinto. Santiago: Editores Uqbar, 2010. 19-26.

Ruiz, Raúl. Poética del cine. Trad. Waldo Rojas. Santiago: Editorial Sudamericana Chilena, 2000. Entrevistas escogidas-filmografia comentada. Ed. Bruno Cuneo. Santiago: Editorial UDP, 2013. 